\title{
Der Gottesstaat des Esad Bey \\ Eine Muhammad-Biographie aus der Sicht eines jüdischen Konvertiten zum Islam unter besonderer Berücksichtigung der Dimension des Politischen
}

\author{
FARID HAFEZ (Vienna)
}

\begin{abstract}
Esad Bey's theocratic state. A Muhammad biography from the perspective of a Jewish convert to Islam with special consideration for the political dimension.

This paper analyses the political dimension of the Muhammad biography written by Esad Bey (19051942), a.k.a. Leo Noussimbaum, a Jewish convert to Islam, who lived and worked as a writer in Berlin/Germany. Esad Bey, a Baku-born (Azerbaijan) Jew, who became a Muslim in an early stage of his life, had written 16 books at the age of 30, one of which became a world-bestseller. Esad Bey was a mostly unkown public figure until Tom REISS finished the first well researched biography in 2008; yet he still continues to relatively unkown to Muslim audience. The biography of Muhammad was the second biography of Esad Bey, following his initial biography on Stalin.

The biography, that was published in 1932 in German language, is highly influenced by it's time, the concurring ideologies of fascism and communism as well as the pan-Islamist thinking of Esad Bey. In a time of social assimilation of Jews, Esad Bey chose to emphasize his Muslim identity inwardly as well as outwardly through wearing the traditional Ottoman Fez. The biography Mohammed is the product of a sirah influenced by the traditional writing of Muslims and that of Orientalists. On one side, Esad Bey tries to make his Western readership of the 1930s more sympathetic to Islam, while on the other side it reads very much as a cry to Muslim political renewal. Focus of his narration is the state that is characterized in many different ways (theocratic, despotic, socialist, democratic, etc.). This papers aims at analyzing his understanding of the theocratic democratic Islamic state as told in his biographical writing.
\end{abstract}

\section{Esad Bey und seine biographischen Arbeiten}

\section{Der wenig erforschte Esad Bey}

Esad Bey, Leo Noussimbaum, Kurban Said. Diese Namen standen für einen Schriftsteller, der im Alter von 30 Jahren 16 Bücher veröffentlicht hatte. Mit Ali und Nino erhielt er Weltberühmtheit. ${ }^{1}$ Mit Tom ReISs' Der Orientalist. Auf den Spuren von Essad-Bey er-

1 Neue Studien von Betty BLAIR und Könül SAMEDOwA, die in der US-amerikanischen Zeitschrift Azerbaijan International veröffentlicht wurden, sprechen Esad Bey dabei die Autorenschaft ab und finden in dem aserbaidschanischen Schriftsteller Jusif Vazir Tschamansaminli den tatsächlichen Urheber (AI, 2011).

Journal of Arabic and Islamic Studies • 13 (2013): 1-21

(C) Farid Hafez, Department of Oriental Studies, University of Vienna, Austria 
schien 2005 eine erste umfassende und auf viel Datenmaterial beruhende Biographie (die deutsche Übersetzung folgte 2008). ${ }^{2}$ Auch der Orientalist Gerhard HöPP (1942 - 2003) hat zum Leben von Esad Bey (im Folgenden kurz „EB“) geforscht. ${ }^{3}$ Noussimbaums muslimische Perspektiven und hier v.a. seine politisch-theoretische Ideenwelt erhalten bei REISS wenn überhaupt - nur peripher Aufmerksamkeit (REISS 2008: 151f.). Dabei scheint es, als habe REISS sich in dieser Hinsicht in erster Linie auf die Arbeiten des Orientalisten HöPP gestützt (HÖPP 1997: 5f.), ohne hier selbständig weiterzuforschen. Diese Lücke zu füllen ist Absicht des vorliegenden Artikels. Nicht zuletzt ist zu beachten, dass der Journalist ReISS selbst jüdischer Abstammung ist und womöglich dieser Komponente seiner Identität mehr Aufmerksamkeit zu schenken imstande war. ${ }^{4}$ So verortet REISS den Schriftsteller EB in einem ,jüdischen Orientalismus“, der „das Judentum und den Islam, den Osten und den Westen, auf eine nahezu unwirkliche Weise in einer gemeinsamen, harmonischen Vergangenheit miteinander verbunden sah" (2008: 275). REISS ordnet EB in eine Kette jüdischer Orientalisten, wie Benjamin Disraeli, Arminius Vambery und William Gifford Palgrave, die „sich als ,Orientalen' ausgegeben und verkleidet" hatten, „um sich von einer Welt abzuheben, in der sich Juden wie ihre Väter allzu gut assimiliert hatten“ (2008: 276). Wenn REISS etwa über die politische Ordnung von damals zu sprechen kommt, so erklärt er EB's pro-monarchistische (2008: 299) und pro-osmanische Einstellung mit dem von ihm konstatierten Wohlwollen seitens der Juden von damals gegenüber den Großreichen, in denen Juden unter toleranter Herrschaft leben konnten (2008: 152). Aber auch die Tatsache seiner muslimischen Beerdigung erhält keine ernstzunehmende Beachtung. So ist in den unveröffentlichten Tagebüchern eines Armin T. WEGNER über die letzten zwei Lebensjahre Noussimbaums, die der Orientalist HöPP zugänglich machte, zu lesen, die „vorgeschriebenen moham. Gebräuche" seien gemacht worden. ${ }^{5}$ Dieser Umstand legt eine ernsthafte Identifikation EB's mit dem Islam nahe. Mir scheint hier, als hätte REISS der jüdisch gefärbte Blick wichtige Dimensionen des muslimischen Teils seiner Identität übersehen lassen.

\section{Esad Bey, der Muslim}

Noussimbaum begann sich bereits vor seinem 10. Lebensjahr mit dem Islam zu identifizieren (REISS 2008: 40), nahm den Islam aber offiziell erst 1923, mit 18 Jahren, in der Botschaft des Osmanischen Reiches zu Berlin an (2008: XXVI, 242). Er war nicht der einzige Konvertit, der publizistisch tätig war. Hamid Hugo Marcus war ebenso jüdischer Herkunft und publizierte nach seiner Konversion in der Muslimischen Revue (MOTADEL 2009: 115121), einer Zeitschrift, die die Ansichten der Ahmadiyya-Lahore propagierte (WOKOECK 2009: 124), denen EB höchstwahrscheinlich nicht nahestand, da er kein einziges Mal in

2 Wobei der Ökonom und Bey-Forscher Wilfried FuHRMANN einige Mängel in der Arbeit ReISS' feststellt (FuHRMANN 2008: 34, Fußnote 42).

3 Drei Artikel hat er veröffentlicht: HöPP 1996, HÖPP 1997, HöPP 2001.

4 So etwa, wenn REISS davon spricht, dass BEY „gleichzeitig Jude, Orientale und Deutscher“ war, „niemals aber machte er sich eine dieser Identitäten so sehr zueigen, dass die anderen ausgeschlossen waren“ (REISS 2008: XXVI f.). REISS hat meines Erachtens der Dimension seiner islamischen Identität zu wenig Aufmerksamkeit geschenkt.

5 Tagebücher Armin T. WeGNERs, <http://www.zmo.de/biblio/nachlass/hoepp/02_10_136.pdf> [01.01. 2011]. 
dieser Zeitschrift, die von 1926 bis 1940 existierte, publizierte. ${ }^{6}$ Noussimbaum nützte im islamisch-literarischen Spektrum das panislamistische „Islam-Echo“ (HöPP 1997: 6). EB stellte seine muslimische Identität in einer Zeit, in der alte Osmanen sich ihrer Identität entledigten, selbst mit seinem Äußerlichen in den Vordergrund (REISS 2008: 153). Das ist insofern nicht unbedeutend, als der Turban und speziell der Fez zu dieser Zeit eine panislamische Symbolik nach außen transportierten (MOTADEL 2009: 105). Das bedeutet nicht, dass seine jüdische Identität von keiner Relevanz mehr gewesen wäre. So wurde EB unter dem Namen Nussembaum im Jahre 1931 nicht nur als ,jüdischer Geschichtsschwindler“ auf einen antisemitischen Index gesetzt, sondern auch von muslimischen Glaubensgeschwistern öffentlich als solcher bezeichnet (WeISS 2008: 213, 329). Das Jüdische wurde oftmals gemeinsam mit dem Muslimischen als eine Gefahr betrachtet. Muslime und Juden waren in den 1920er Jahren eine Einheit in der Sicht deutscher Gruppen (2008: 225, 292). EB war 1923 im Alter von 18 Jahren Gründungsmitglied der Islamischen Gemeinde in Berlin und half 1924, die studentische Vereinigung Islamia ins Leben zu rufen (2008: 244), aus der das Islam-Institut hervorging, die eine Islambibliothek sowie ein Islamarchiv beheimatete (MOTADEL 2009: 113). Er selbst zählte sich in politischer Hinsicht zu den Panislamisten und hielt „Vorträge über das Kalifat“. Nach REISS war EB als „kosmopolitischer Osmane" aufgrund der Hinwendung zum Nationalismus unter vielen Muslimen eher AuBenseiter (2008: 244ff.). Später sollte er auch von seinen muslimischen Mitstreitern stark kritisiert werden. Ausgehend von der Kritik an seinem Buch „Öl und Blut“ wurde später auch seine Muhammad-Biographie aufs Heftigste kritisiert. Eine Prager muslimische Zeitung sah darin einen „scharfen und raffinierten Angriff gegen unsere Glaubensbrüder in Asien und Afrika“" (2008: 265). ${ }^{7}$ Angriffen war er auch aus der neu gegründeten Türkei ausgesetzt (2008: 265), womöglich unter dem Aspekt seiner pro-osmanischen (und damit antitürkischen) und pro-saudischen Positionierung, die auch in der Muhammad-Biographie klar zum Ausdruck kommt. EB betrachtete sich als Panislamist, wie aus vielen Schriften hervorgeht (BEY/VON WEISL 1936: 43-61 und REISS 2008: 244ff.), der sich auch in organisatorischer Hinsicht in Berlin einer panislamistischen Gruppe anschloss (HöPP o.D.: 3). Dieser Gruppe trat er bei, nachdem die Islamia sich unter dem Leiter Tschlebi so sehr politisiert hatte, dass der alte Vorstand der Islamia aufgelöst wurde (HöPP o.D.: 2). HÖPP schreibt ausführlicher als REISS über EB's politisch-religiöse Positionen (HöPP 1997:

6 Alle Ausgaben sind online unter http://berlin.ahmadiyya.org/m-rev/ abrufbar. Es ist zu erwähnen, dass in diesem Periodikum nicht nur Anhänger schrieben, sondern selbst Menschen nichtmuslimischen Glaubens sowie internationale Autoren.

7 So dürften manche Darstellungen tatsächlich den allgemeinen Interessen der Muslime von damals nicht gefallen haben. Besonders der Aspekt der Gewalt dürfte der allgemeinen Darstellung des Islams durch die muslimische Gemeinschaft widersprochen haben. Bey sprach stolz von den „Sturmabteilungen des Islam“ (2002: 204) und meinte etwa: „Die Muslims haben starke Muskeln, blickten bedrohlich drein und klirrten mit ihren Waffen" (2002: 205). Aber auch orientalistische Erzählmuster wie der schäumende Mund des Propheten bei der Offenbarung (2002: 103) oder die Charakterisierung Muhammads mit den Worten „er vergoss Blut, herrschte brutal und rücksichtslos, handelte listig und verschlagen, kriegerisch und weise“ (2002: 208) dürften wenig Anklang gefunden haben. BEY verwendete Begriffe wie den Harem (2002: 276, 287) neben einer Erklärung der guten Stellung der Frau im Islam. Aber auch die kriegerische Seite des Islams passt für BEY in ein in sich schlüssiges Konzept, wie später noch gezeigt wird. Der Bruch innerhalb der Gemeinschaft Islam-Institut dürfte aber auch politische Gründe gehabt haben (HÖPP 1997: 8). 
13ff.). Seine Publikationen erhalten jedoch im Zuge der Veröffentlichungen von Tom REISS kaum Beachtung in der öffentlichen Wahrnehmung. Hingegen zweifelt der Ökonom Wilfried FuHRMANN, welcher die Domain <www.essadbey.de> betreibt, die muslimische Identität EB's stark an. In der folgenden Darstellung geht es nicht darum, die religiöse Identität des EB herauszuarbeiten. Auch geht es nicht darum, EB als puren Panislamisten darzustellen und seine weiteren Identitätsfacetten $\mathrm{zu}$ ignorieren. Vielmehr wird in Anerkennung der unterschiedlichen Identitäten des Leo Noussimbaum ein Aspekt behandelt, der meiner Ansicht nach in den meisten Darstellungen nur peripher gewürdigt wird. Die Konzeption des Gottesstaates in der Biographie über den letzten Propheten gewährt besonders in der gemeinsamen Betrachtung mit dem Werk „Allah ist groß“, auf das zeitweise eingegangen wird, Einblick in das panislamistische Gedankengut des EB.

\section{Esad Bey als Biograph}

EB tat sich früh als Biograph hervor. Von seinen 16 veröffentlichten Werken, die er zwischen 1928 und 1938 publizierte, waren sechs Werke im engeren Sinne biographische Arbeiten. Die Liste reicht von Stalin über Lenin bis hin zu Nikolaus II, Königin Elisabeth und Reza Schah. Die Biographie Muhammads erschien im Jahre $1932^{8}$, ein Jahr nach der Veröffentlichung seiner ersten biographischen Arbeit, jener über Stalin ${ }^{9}$, die die erste Biographie über Stalin überhaupt war (MONTEFIORE 2008: 189). ${ }^{10}$

8 Link zum Datensatz in der Deutschen Nationalbibliothek: <http://d-nb.info/575271558>.

9 Siehe <http://d-nb.info/575271612>.

10 Der Stalin-Biograph Simon Sebag MonTEFIORE meint in Bezug auf Esad Beys Biographie, dass seine „unbelegten Anekdoten [...] sich häuflich [sic!] als korrekt erweisen“ (MONTEFIORE 2008: 217). Ganz im Gegenteil weist Noussimbaum sorgfältig darauf hin, wann es sich um „Legenden“ handelt (BEY 2002: 59, 73). „Legenden“ sind bei Bey zwar per se nicht erfunden (2002: 178), jedoch weist er darauf hin, dass das eine oder andere über eine Person oder einen Umstand kaum erforscht ist (2002: 72). Dass er mit anderen Prophetenbiographien gearbeitet hat, zeigt sich auch in der Verwendung direkter Zitate. So etwa die Worte Waraqa ibn Naufals zum Propheten, als er dessen Offenbarung erläuterte (2002: 98f.). Diese setzt sich aus zwei Zitaten auseinander, die sich bei der ältesten Prophetenbiographie von Ibn Ishaq befindet (IBN ISHAQ 1999: 46f.). Ebenso ein Koranzitat (BEY 2002: 99), das eins zu eins der erstmals 1888 veröffentlichten Übersetzung durch den Orientalisten Friedrich Rückert entnommen wurde (RÜCKERT, 2009: 573). Jedoch dürfte er sich auch anderer Übersetzungen oder seiner eigenen bedient haben, wie andere Koranübertragungen zeigen, die nicht dem Text von Rückert entsprechen (BEY 2002: 100). So auch die 93. Sure, die Bey als zweite Offenbarung angibt. Hier übersetzt er frei, nur wenig an Rückert anlehnend (2002: 101). Aber auch im Zitieren von Dialogen und Aussprüchen des Propheten bleibt Bey recht nah an den Quellen (2002: 133), wenn er auch in so manchen Darstellungen durch seinen romanartigen Erzählstil sehr ausschweifend wird (2002: 133). Seinen Erzählstil beschreibt HÖPP als „schillernde Mischung von Phantasie und Realität, Unterhaltung und Information“ (HÖPP o.D.: 5). Die Erzählungen decken sich bis in weite Details aber mit den klassischen Überlieferungen. Um nur ein Beispiel zu nennen: Die Namen der ersten Konvertiten zum Islam (BEY 2002: 103f., IBN ISHAQ 1999: 49-52). Einige Geschichten und v.a. theologische Positionierungen Beys erscheinen jedoch umso verworrener und mehr eine Projektion seiner persönlichen Lebensumstände zu verdanken zu sein, als der Recherche. Wie bereits hinsichtlich der muslimischen Kritik an seiner Person in den 1930er Jahren angesprochen wurde, passen manche Erzählmuster durchaus in orientalistische Darstellungen. 


\section{Die Wüste ist das Arabische}

EB's Biographie beginnt einführend mit einer Einleitung über die Welt vor der Zeit des Propheten (BEY 2002: 21-70). Damit gleicht er den klassischen Muhammad-Biographien wie jene von IBN IsḤĀQ (704-767), auf dessen Muḥammad-Biographie die Mehrheit aller akademischen wie auch populärwissenschaftlichen Arbeiten zurückgehen (JANSEN 2008: 19ff.). Mit der einführenden Darstellung der Wüste wurde nach Tilmann NAGEL die Verklärung der Wüste festgeschrieben. Diese Darstellung des Islams als „Religion der Wüste [...] begann schon im 9. Jahrhundert in den Metropolen des noch jungen islamischen Reiches. Sie gelangte zu den gebildeten Schichten Europas im Zeitalter der Romantik“ (NAGEL 2010: 17) und so auch zu EB, dessen Erzählung mit der Wüste des Propheten beginnt (BEY 2002: 21-27). Für EB ist die Wüste der von den umliegenden Zivilisationen missachtete Ort, ein unangetasteter und unveränderter Fleck, an dem Wildnis und Barbarei herrschten (2002: 21). Er beschreibt die arabische Halbinsel als von felsigen, unzugänglichen Küsten umliegend, durch das Meer getrennt, isoliert durch die Wüsten im Norden wie im Süden (2002: 22). Die Wüste wird zur „die Wiege und Grab alles Arabischen“ (2002: 24). Dies habe dazu geführt, dass auch der arabische Mensch sich nicht verändert. So sei das Volk der Araber „starr in seiner Art, wie die Wüste, der es entstammt, in der es lebt, von der es sich nicht trennen kann“ (2002: 27). Die Wüste als Ort der unbefleckten Reinheit und der durch keinerlei Menschenwerk verstellten Klarsicht war Topos so mancher zivilisationskritischer Autoren, die sich mit dem Islam auseinandergesetzt hatten (NAGEL 2010: 17). Die weite Öde und Einsamkeit, die im Zuge unendlicher Karawanenritte durch die Wüste erlebt werde, habe den Menschen dazu gezwungen, sich um das Wesentliche zu kümmern. Das Hirn des Wüstenmenschen sei „durch wenige Erscheinungen gereizt, es hat Zeit zum Ruhen, Grübeln und Denken [...] Nur wenige Gedanken finden in ihm Platz. Diese Gedanken aber sind fest und tief in seiner einfachen Seele verankert" (2002: 26f.). Dabei unterscheidet er zwischen zwei Teilen des arabischen Volkes, die sich antagonistisch gegenüberstehen: Den Nomaden und den Städtern. Interessant ist hierbei die normative Positionierung Noussimbaums, die sich nicht nur pro-nomadisch, sondern auch pro-östlich im Gegensatz zum Westen, offenbart (BEY 2002: 29). EB würdigt das „System“ der Sippe, denn diese würde dem Araber ,alles, was der moderne Staat seinen Bürgern an Bequemlichkeit und Sicherheit bieten kann, und noch vieles mehr" garantieren (BEY 2002: 30f.). Die arabische Lebensweise verteidigend meint er: „Der Nichtorientale irrt. Das Gesetz der Blutrache ist komplizierter und vielseitiger als die meisten Gesetze Europas“ (BEY 2002: 34). Auf Noussimbaum übte die Lebenswelt der Araber eine große Anziehung aus (REISS 2008: 70), ähnlich der Faszination, die Leopold Weiß alias Muhammad ASAD in seinem Roman Der Weg nach Mekka beschreibt (ASAD 2009: 24, 69). Interessant ist in dieser Hinsicht auch die Rolle, die die Wüste in seinem autobiographischen Roman erhält. Dort heißt es: „Unverändert blieb die unausrottbare Liebe zu den geheimnisvollen Schnitzereien und Schnörkeln der orientalischen Manuskripte, die Liebe zu den fernen Wüsten, Oasen und Torbögen der alten Paläste“ (FUHRMANN 2008: 12).

EB bewundert den Beduinen, denen Gott vier Gnadengeschenke gegeben hätte: Den Turban, das Zelt, das Schwert und die Dichtkunst (,schöne Kunst des freien Gesangs“). Letzteres sei das einigende Glied aller arabischen Sippen und mache sie zu einem Volk; „eine Sprache von unerhörtem Reichtum“ (BEY 2002: 41). „Der Spott des Dichters“, so 
Noussimbaum verklärend, sei „gefürchteter als das Schwert“ (BEY 2002: 44). Noussimbaum sieht in den Wüstenarabern, die ihre Religion nicht ernst nehmen würden (BEY 2002: 38), aber auch ein Volk, das kein Volk ist. Einigkeit kennen sie nicht. Denn der Glaube an den Gott der Ka ba, die durch den Erzvater Abraham errichtet wurde, sei längst verblasst gewesen (BEY 2002: 65). Die Rolle von Religion bei den Arabern vor Muhammads Prophetie charakterisiert EB eher aus der Sicht eines Ökonomen, was bereits bei Autoren wie Hubert Grimme 1892 sowie J. Wellhausen und C.C. Torrey jeweils $1897 \mathrm{zu}$ beobachten war (ALI 1997: 95f.):

Doch glaubten die Kaufleute selbst nur wenig an die Reklame-Idole ihrer Götter. Die alte Religion war tot. Was übrig blieb, war Reklame, inhaltlose Zeremonie, überholter Kultus, Unfug und Barbarei. Viele in Mekka fühlten es, viele wussten es. [...] Aber da diese Götter Reichtum der Stadt bedeuteten, durfte man nicht gegen sie verstoßen. Das verbaten sich die Kaufleute energisch und entschieden. (Bey 2002: 82)

EB benutzt diese Charakterisierung des arabischen Volkes als einfach und primitive auf der einen Seite sowie die Glorifizierung des Beduinenlebens auf der anderen Seite, um die Ausbreitung des Islams in den späteren Jahren umso mehr als Wunder deuten zu können. So schreibt EB, dass Muhammad ,aus der Wüste Arabiens, aus dem Lande der Bettler und Landstreicher [...] aus dem Nichts eine Welt zu erschafften" imstande war (BEY 2002: 57). Der Geist, der dies zustande brachte, war Muhammad (BEY 2002: 70). Ebenso ist die Darstellung des Propheten Muhammad als eines einfachen, des Lesens und Schreibens unkundigen Menschen, zu deuten, um den Koran als „Wunder [..., als] unübertroffene[n] Höhepunkt der arabischen Sprache“ zu präsentieren (2002: 112). Hier steht der Autor ganz in der Tradition der $i^{\prime} \check{g} \bar{a} z$ al-qur'ān-Literatur.

\section{Aspekte des Religionsverständnisses von Esad Bey ${ }^{11}$}

In vielen Punkten entsprechen die Ansichten EB's zur islamischen Religion traditionellen Anschauungen wie auch damaligen Interpretation, wenn etwa von den vier Dogmen des Islams (Glaube an Gott, die Gleichheit der Menschen, ${ }^{12}$ das Jenseits) und den „,ünf Säulen“ (2002: 394) die Rede ist. EB verwirft die Übersetzung von „Islam“ als „Hingebung an Gott" und verweist - mit philologischer und inhaltlicher Expertise - auf die Bedeutung von Friede, Schutz und Rettung (BEY 2002: 109). Islam heißt nach EB „friedvolle Ergebenheit“ (EB/VON WEISL 1936: 13). Der Islam wird als allumfassend präsentiert (BEY 2002: 109), was einen Navid KERMANI zu dem Urteil geführt haben dürfte, EB würde einen schieren Fundamentalismus vertreten (KERMANI 2002). Muhammad als Überbringer der abschlieBenden Offenbarung (BEY 2002: 109-112),,wollte Frieden mit den Juden. Er glaubte an die

11 Über das Religionsverständnis Noussimbaums gibt das Kapitel „Der praktische Islam“ (2002: 394-401) Auskunft, das sich ausschließlich mit Grundzügen des Islams auseinandersetzt. An anderen Stellen der Prophetenbiographie finden sich immer wieder Stellen, die sich mit der Religion als solcher auseinandersetzen. Darüber hinaus finden sich auch im Werk ,Allah ist groß. Niedergang und Aufstieg der islamischen Welt von Abdul Hamid bis Ibn Saud“ zahlreiche Erläuterungen über die Religion des Islams.

12 Die „Gleichheit der Menschen“ sieht er als eine der drei Lehren des Reformers Ğamāl ad-Dīn al-Afg̉ān̄̄ (BEY/VON WEISL 1936: 56) 
Einheit von Islam und Judentum“ (2002: 198) ${ }^{13}$ In diesem Sinne kann auch ReISS' Sicht auf EB als jüdischer Orientalist, der die Einheit von Juden und Muslimen propagierte" (REISS 2008: 275-294), nachvollzogen werden. EB betrachtete Muhammad aber als lernenden Menschen, der schlussendlich erkannte, dass die jüdischen Gemeinden in Medina sich gegen Muhammad verschworen, womit die Vertreibung dieser legitimiert wird. So vergleicht er an einer Stelle Muhammad mit Luther, die beide „Meister der Vorsicht, der Umsicht, der Zurückhaltung, gleichzeitig aber von Bekennermut, fester Überzeugung getragen“" waren (2002: 180). Der Prophet wird zudem als Pädagoge präsentiert: „Beispiele, Bildung, Diskussion“ waren die Mittel, seine Botschaft zu verkünden (2002: 136). Dieses Element der Erzählstruktur ist EB eigen. Darin ähnelt er dem länger wirkenden Iraner Ali Dashti (1896-1981), welcher den Propheten ebenso als „gewöhnlichen Mensch [...] mit Stärken und Schwächen“" beschrieb (NAGEL 2010: 12). Dass die Entwicklung des Lebens des letzten Prophetens Anfang des 20. Jahrhunderts vermehrt mit der Erklärung durch materielle Faktoren geschah, kann auch bei anderen Prophetenbiographien wie jene von William Muir, D.S. Margoliouth und W. Montgomery Watt gesehen werden (ALI 1997: 95). Wie sehr EB Kind seiner Zeit ist, offenbart seine Überzeugung, der Islam sei ein „wunderbares, nüchternes, positivistisches Gebäude" (2002: 111). Der Prophet argumentierte sowohl mit Logik wie auch mit dem ,,̈̈bersinnlichen Beweis“, dem „Worte Gottes“ (2002: 104). An anderer Stelle heißt es: „Die Religion, die er den Völkern verkündete, war lediglich ein gesteigerter Positivismus. Alles Übersinnliche, alles, was verstandesmäßig unfassbar schien, war ihm tief verhasst“ (2002: 136). Den Erzählungen EB's nach war die Lehre der Vereinbarkeit von „moderner Wissenschaft und Koran“ eine zentrale Deutung des Panislamismus (EB/VON WeISL 1936: 57). Dieser Darstellung des Islams als dem Verstand verpflichtete Religion ist in den Erzählungen Noussimbaums immer wieder an die Trockenheit und Einfachheit der Wüste gekoppelt (BEY 2002: 26). Andererseits erhält diese Darstellung des Islams auch in der Kontrastierung zum Christentum ihre Wirkung: „Die Freude am eigenen Körper, an der eigenen Kraft und Schönheit wurde auch ein wesentlicher Zug des Islam. Tief verhasst [...] waren für Mohammed die Asketen und Büßer der Christen, die das Fleisch und die Freude des Fleisches verdammten“ (BEY 2002: 87). Der Islam ist hier für EB die Antithese zum Christentum. Körperlichkeit und Sexualität ist eine Tugend, nichts Teuflisches (2002: 116f.), die Ehe ist privatrechtlich und nicht kirchlich (2002: 400). Der Islam wird zur Religion ohne Vermittler, ohne Weihe, ohne Einteilung der Menschen in Priesterschaft und Laien (2002: 116f.). Die Wüste erhält eine immanente Stellung für das Wesen der islamischen Religion. In einer weiteren Darstellung stellt EB den Kern der islamischen Religion folgendermaßen dar:

Der Islam kennt keine Fantastik, ist logisch aufgebaut und übersichtlich wie das Kontobuch eines Kaufmanns. Er kennt nur wenige Grundsätze, doch diese regeln alle Beziehungen zwischen Mensch und Gott und den Menschen untereinander, denn Islam ist nicht nur Religion, sondern auch soziale Lehre. In phantastischen, traumhaften

13 Nicht in das jüdische Weltbild passt die positive Hervorhebung Jesu. Dieser positive Bezug von EB beschreibt das Wesen des Propheten Jesu als einen in der islamischen Religion höchst anerkannten, der entsprechend der klassischen Darstellung nicht gekreuzigt und dessen Botschaft im Nachhinein verdreht wurde (2002: 116). Diese Darstellung ist womöglich der deutschen Leserschaft geschuldet, zeigt aber nicht zuletzt, wie sehr sich Noussimbaum zu einem EB in religiöser Hinsicht gewandelt hatte. 
Visionen empfing Mohammed eine nüchterne, rationelle und dennoch in ihrer exakten, rationalistischen Einfachheit überwältigende Lehre. ,Man muss an den einzigen Gott glauben, gut zu den Menschen sein, seine Leidenschaften beherrschen, die Feinde des Glaubens bekämpfen und an die Vergeltung seiner Taten nach dem Tode glauben'. In diesem einzigen Satz ist die ganze Lehre enthalten. (BEY 2002: 115)

Seine positivistische Herangehensweise wird auch daran erkennbar, dass er sowohl das Gebet wie auch das Fasten im Monat Ramadan als Formen und Übungen in der Disziplin darstellt. Mit dieser Betonung des Rationalen kann EB in Verbindung zu einem oftmals bedienten Topos der muslimischen Gemeinschaft in Berlin gestellt werden. So zeigt der Historiker David MOTADEL in seiner Analyse der ,vier islamisch-bürgerlichen Themenkomplexe“, dass der Islam oftmals als das „Einfache, Vernünftige, Rationale“ präsentiert wurde (Motadel 2009: 116f.). Die Gebete ,stärkten die Seele, erweckten das Gefühl der Zusammengehörigkeit und der Disziplin“, so EB (BEY 2002: 210). Die Ursprünge der Militär- und Wüstenromantik sieht KERMANI in EB's Schriften im Kulturskeptizismus des frühen 20. Jahrhunderts, Nietzsche, Ernst Jünger und Oswald Spengler (KERMANI 2002). Dieser Behauptung kann nicht völlig widersprochen werden. Sie muss aber deutlich eingegrenzt werden. So finden sich Grundzüge romantischer, zivilisationskritischer Topoi wie die Umkehrung von Zivilisation und Barbarei (HERMAN 1998: 40), das Hochhalten von Werten wie Tugend und Heroismus (HERMAN 1998: 54), oder die zerstörende Kraft der Gelüste (HERMAN 1998: 56). Aber es finden sich gleichzeitig ebenso in eine ganz andere Richtung weisende Fortschrittsgedanken wie jene Hegels, wonach der Mensch durch sein eigenes Werk seinen Traum erfüllen könne und den Staat dazu als Mittel gebrauche (HERMAN 1998: 45). Einem Oswald SPENGLER hat EB womöglich den Führergedanken abgewinnen können (HERMAN 1998: 219). Über dessen Darstellung und Reduzierung des Islams auf aristokratische Züge (SPENGLER 2000: 1090f.) dürfte er weniger erfreut gewesen sein. Darüber hinaus war EB nicht wie den Kulturpessimisten seiner Zeit die Zerstörung einer kranken, modernen Gesellschaft wichtig (HERMAN 1998: 17). Seine Arbeit als panislamistischer Autor der Muhammad-Biographie ist eher in die Zukunft und visionär ausgerichtet. In diesem Sinne scheint mir eine differenziertere Betrachtung angebracht.

EB meint einerseits, dass die Religion des Islams ,in ihrer Verleugnung jeglicher Mystik alles andere weit übertrifft" (2002: 118) und ein logisches Gerüst an Lehren und eine Perfektion menschlicher Ordnung, weniger aber eine Spiritualität und schon gar kein „Tanz und Musik“ (2002: 120, 203) kennt sowie jedem Fatalismus abgeneigt ist (2002: 211). Andererseits zitiert er in Anerkennung den ,großen Mystiker des Islam Galal ad-Din Rumi“ als Vertreter des inneren Weges des Islams (2002: 179) und erwähnt die Masnawi des Rumi auch in seiner Autobiographie (FUHRMANN 2008: 26). Er dürfte also nicht dem Sufismus in seiner theoretischen Lehre abgeneigt gewesen sein, wie Navid KERMANI meint (KERMANI 2002). Nimmt man die Gesamtheit der Werke EB's zusammen und betrachtet ebenso seine Liebesgeschichten, so muss ein differenzierteres Bild von EB gemalt werden. Interessant ist aber dennoch, dass Muhammads religiöse Seite insgesamt kaum ins Gewicht fällt und erst zunehmend zum Ende der Erzählungen seines Lebens relevant wird (BEY 2002: 363-369). Die Dimension der islamischen Spiritualität und des Jenseitsglaubens erhält lediglich im Kapitel „Das Paradies der Frommen“ (2002: 388-393) mehr Platz. So war es für EB aber trotz seiner Betonung des Positivismus und der Logik schlussendlich 
der Glaube, der Muhammad erlaubte, eine Herrschaft zu begründen und Gebiete zu erobern (2002: 389). Darin ähnelt er dem britischen Orientalisten Richard BELL (1876-1952), der in den 1930er Jahren ebenso die politischen Dimensionen des Propheten berücksichtigte, seine letztendlich religiöse Ausrichtung aber in den Mittelpunkt stellte (ALI 1997: 100f., BELL 1930: 121f.). Auch Maxime RODINSON wird später diese Einschätzung teilen (RODINSON 1975: 207f.).

In der Darstellung des Propheten als Mensch, der „,von jeder Sünde eine begeht und von jeder Sünde eine bereut und seine Reue verkündet“ (2002: 153), weicht er von den muslimischen Erzählungen deutlich ab. Jesus wird dabei als sündenloser als der Prophet selbst dargestellt (2002: 116). Dass diese Sündhaftigkeit des Propheten einem ganz konkreten Zweck dient, wird in der Darlegung der politischen Biographie ersichtlich. Schlussendlich ist es auch Muhammad, der in seiner Einzigartigkeit wie ,niemand anderer in der Welt [...] den Sumpf der Sünde reineren Herzens verlassen“ hat (2002: 208). Muhammad bleibt in der Darstellung EB's trotz der großen Triumphe stets ein einfacher Mann, der den Hof fegte, seine Kleider flickte (2002: 252). Eigentümlich ist auch die teilweise harte Ablehnung des Prophetengefährten Ali, dem er Faulheit, Führungsschwäche und andere schlechte Eigenschaften unterstellte (2002: 288, 353), andererseits aber Treue und Autorität zusprach (2002: 360). Die Gegnerschaft gegen Ali wird teilweise so begründet, dass dieser der Partei anhing, die das Erbschaftsprinzip vertrat, welches für EB mit den Idealen einer theokratischen islamischen Demokratie unvereinbar war (2002: 287).

\section{Politische Anschauungen}

Dass EB selbst eine hochpolitische Figur darstellt, zeigt sich auch anhand seiner Darstellung der Prophetenbiographie. So heißt es in Bezug auf religiöse Debatten: „Wie heute die Politik, stand damals Gott im Mittelpunkt des Weltgeschehens“ (BEY 2002: 81). EB's Erzählung spitzt sich jeweils auf das Politische zu: „Wurde der Glaube an die Einmaligkeit seiner Erscheinung erst einmal erschüttert, so war das ganze Gebäude des Staates untergraben. Mit der Einmaligkeit seiner Erscheinung stand und fiel der Islam“ (2002: 350). Die Religion des Islams wird für EB gleichbedeutend mit der Staatlichkeit. Der Islam, das ist für EB „Religion, Weltanschauung und Recht“ zugleich, ein allumfassendes System (2002: $109,182)$. In diesem Sinne beschreibt er die muslimische Gemeinschaft nicht nur als religiöse Gemeinde, sondern auch als „Kern eines Staates [...] Religion, Weltanschauung und Recht". Interessant ist hierbei, dass die Zugehörigkeit zu dieser Gemeinde bzw. zu diesem Staat nicht religiös definiert wird, sondern als soziales Band. Die zakāt wird in EB's Lesung zum „ersten Versuch einer Sozialversicherung“ und der Prophet selbst zum „Sozialreformer" und „Parteiführer“ (2002: 117f.).

\section{Die Bewegung von unten}

Das erklärt sich in der Deutung des Wirkens von Muhammad in seiner Gesellschaft. Die Gefahr, die Muhammad für die herrschenden Kaufleute von Mekka darstellte, erhält eine ökonomische und sozialrevolutionäre Färbung. Muhammads Kampfansage an die Götter Mekkas war mit einer Destabilisierung des „Fundaments des Reichtums der Quraisch“ gleichzusetzen (2002: 126). Die Attraktivität, die seine Lehre auf Sklaven und besitzlose 
Städter ausübte, war den Herrschenden ebenso ein Dorn im Auge (2002: 127). In diesem Sinne charakterisiert EB Muhammads Aufruhr gegen die „konservativen“ Kräfte als eine „Bewegung des Pöbels gegen die altansässigen Herrscher von Mekka“, als „Kampf zwischen dem revolutionären Propheten und den reichen Kaufherren“ (2002: 139f.). Später sollte auch der Orientalist Maxime RODINSON als bekennender Marxist eine MuhammadBiographie schreiben, in der er ,den Werten der Ideologie und der auf einer Ideologie gründenden Bewegung“ besondere Aufmerksamkeit schenkte (RODINSON 1975: 5f.), wobei ihm von muslimischer Seite auch ein philosophischer Dogmatismus vorgeworfen wurde (BENABOUD 1986: 314). Auch er schreibt ein Kapitel über die Geburt eines Staates (1975: 207-278) und schenkt dem Politischen in seiner Biographie große Aufmerksamkeit. Muhammad habe nach EB als „Revolutionär [...] die Sklaven mit Herren gleichstellen“ wollen (2002: 145). Seine Anhänger waren die „Partei des Propheten, des radikalen Revolutionärs“ (2002: 155). Die Transformation nach der hiğra machte aus dem Propheten ,einen sehr realen Staatsmann und Politiker“ (2002: 170). Die Gefolgschaft Muhammads beschreibt EB als einzigartig in der damaligen arabischen Wüste. Sie hatte zwei Merkmale, die sie vor allen auszeichneten: „Disziplin und innere Haltung“ (2002: 220). So zieht er auch aus der Schlacht von Badr, in der eine kleine Gruppe von 300 Mann gegenüber 950 Mekkanern gewann, die späteren vier „Grundregeln der arabischen Strategie“: „Disziplin und Zusammenhalt der Infanterie, die in geschlossenen Karrees jedem Kavallerieangriff gewachsen war und erst am Ende der Schlacht, als der Feind erschöpft war, auf Befehl des Führers zu einem Sturmangriff überging“" (2002: 221-225).

\section{Eine politische Biographie}

Dass EB das Prophetenleben sehr politisch deutet, ist bereits an den Überschriften der einzelnen Kapitel erkennbar. Eines von vier Überkapiteln titelt „Der Staat Gottes“. Die Überschrift des diesem vorausgehenden Unterkapitels lautet in einem sozialistisch anmutenden Jargon „Der Sprung in die Praxis“, womit EB die Staatswerdung des Islams meint (2002: 177-184, 377). Selbst der Harem wird politisch gedeutet, denn „Liebe, Berechnung und Politik sind im Orient untrennbar" (2002: 287). Wie später auch bei den bereits erwähnten Autoren, Maxime RoDINSON und Ali Dashti, es der Fall ist, wird der Prophet nicht als ausschließlich von Gott geleiteter Mensch dargestellt, sondern als kalkulierender politischer Führer portraitiert (NAGEL 2010: 12, RODINSON 1975: 207-78). Handlungen und Entscheidungen werden stets als Ergebnis sorgfältiger Abwägung seitens Muhammad präsentiert (BEY 2002: 195, 304). Sogar Ge- und Verbote stehen unter einem Kalkül (2002: 251f.). Ähnliches gilt für den Emissär Mus'ab, der als „Diplomat“ strategisch in seiner Verkündung der Botschaft vorging (2002: 191). Dieses Erzählmuster dürfte in einer Zeit der großen Erzählungen (HOBSBAWM 1998: 184-227) womöglich attraktiver gewesen sein; das Profane und Weltliche zu betonen und die Spiritualität im Hintergrund zu lassen. Diese Profanisierung des Propheten ist ein Element, das später oft in orientalistischen sowie in islamistischen Diskursen zu beobachten ist (ALI 1997: 95-113, EUBEN/ZAMAN 2009: 4). EB's Militärromantik (die Kämpfer des Propheten waren die „Sturmabteilungen des Islam“, siehe BEY 2002: 204) wurde von seinen muslimischen Zeitgenossen nicht vertreten. Diese sprachen dem Islam als rationale Religion das Gewalttätige ab. So meinte ein Autor in der Moslemischen Revue 1932: „Mohammed griff nicht zum Schwert. Seine Waffen waren die der Logik und die der Vernunft“ (ABD ELAAL 1932, zit. nach MOTADEL 2009: 
117). Möglicherweise war dies ein Grund dafür, dass EB von seinen muslimischen Glaubensbrüdern angegriffen wurde (REISS 2008: 265). Ebenso wird der Bund der Brüderlichkeit primär politisch gedeutet. So habe Muhammad diesen Bund geschaffen, um die unterschiedlichen Fraktionen der Mekkaner und Medinenser zu vereinen. Nach EB habe der Bund nicht gewirkt, bis die Offenbarung in Sure 8, Vers 72 herabgesandt wurde (BEY 2002: 199). ${ }^{14}$ Die politische Sozialisation EB's dürfte diesen auch zu einer gar politischen Darstellung des Prophetenlebens geführt haben. So schreibt er über die Anfangszeit der Verkündung kurz nach den ersten Offenbarungen: „Mohammed begann sich nach den geeigneten künftigen Mitkämpfern umzusehen. Da er aber vorsichtig, kühl, umsichtig und berechnend war, suchte er zuerst seine Anhänger in dem engsten Kreis seiner Familie“ (2002: 103). ${ }^{15}$

Der Prophet, das war der kalkulierende Stratege, der nach Plan vorging. Oder wie es an anderer Stelle heißt, ein Propagandist (BEY 2002: 104), der in seinem ersten Jahr der Prophetie nur acht Personen um sich sammelte. Drei Jahre sollte er stiller Prediger sein. Seine Gemeinde sollte aus nur 20 Personen bestehen (BEY 2002: 106f.). Jedoch wird das Handeln des Propheten nicht wie bei nichtmuslimischen Orientalisten als reines Kalkül betrachtet. Es steht letztlich unter der Anweisung Gottes, der ihm am Ende der drei Jahre des stillen Predigens die öffentliche Verkündung in alle Welt befahl (2002: 108). Diese Zeichnung, die deutlich die Züge ihrer Zeit trägt, zeigt sich auch in der Begrifflichkeit der Prophetenbiographie. EB verwendet seinerzeit zeitgenössische Begriffe, um das Leben des letzten Propheten zu zeichnen. Muhammad bekleidete nach EB den Posten eines Geschäftsführers (BEY 2002: 79). Die leitenden Sippen Mekkas waren für ihn Bankiers und Kaufherren, Mekka charakterisierte er als Kaufmannsrepublik (BEY 2002: 62). Der Prophet ist sozialer Reformator, zielbewusster Parteiführer (2002: 118, 150), Revolutionär (2002: 145) und gewandter Diplomat und zielbewusster Herrscher (2002: 196). Sein Entsandter nach Yathrib, Mus'ab ibn Umair, wird zum Diplomaten. Seine koranischen Unterweisungen treten dabei eher in den Hintergrund und werden nur beiläufig erwähnt (2002: 168, 192). Ganz im völkischen Vokabular seiner Zeit beschreibt er das Begraben lebendiger Mädchen als naive Eugenik der Wüste (BEY 2002: 34). Dieser Versuch der (dazumal) zeitgemäßen Verwendung von Begriffen kann bei verschiedenen Orientalisten wie etwa Johannes Kramer, der im Zweiten Weltkrieg salam mit Heil übersetzte und bei ilf über Kameradschaft sprach, beobachtet werden (JANSEN 2008: 179f.). Ebenso verhält es sich mit Maxime RODINSON, der über Ideologie, Institutionen und Staatlichkeit spricht (RODINSON 1975: 212-224). Von Negern ist bei EB ebenso die Rede, ohne dies jedoch normativ entwertend zu meinen (BEY 2002: 46, 119, 140). Seine Kritik am herrschenden Materialismus seiner Zeit klingt auch in der Kritik an den Polytheismus durch. Diese nannte er Reklame-Idole ihrer Götter (BEY 2002: 82). Mekka selbst kennzeichnete EB als materialistische Stadt (2002: 141). Hier dringt ein kulturpessimistischer Ton, der materiellen Wohlstand als gegen die Kreativität und Lebendigkeit gerichtet sieht (HERMAN 1998: 57), durch. Später sollten Muhammad-Biographen wie jene des französisch-marxistischen Orientalisten Maxime RODINSON (1915 - 2004) den ökonomischen und gesellschaftlichen Faktoren mehr

14 Nach BEY ist es Sure 8, Vers 73 und nicht Vers 72

15 Sehr ähnlich beschreibt Maxime RODINSON Muhammad als scharfsinnigen, geschickten und geduldigen Politiker (RODINSON 1975: 207). 
Aufmerksamkeit schenken, die die Entwicklung Muhammads beeinflussten, und sogar so weit gehen, Muhammad mit Stalin zu vergleichen (JANSEN 2008: 22), was Bey als AntiBolschewist nie zu tun gewagt hätte.

So wird die hiğra nicht etwa unter dem Aspekt der steigenden Unterdrückung erzählt. Vielmehr war es aktives Handeln, das ihr zugrunde lag. Vergleiche etwa folgende Darstellung: „Er besaß kein Mittel, sie [die Feinde, Anm.] in Frieden zu bezwingen. Deshalb suchte der Gesandte Gottes mächtige Kämpfer, kriegerische Sippen und mutige Glaubensbrüder, die ihm den Weg zur Wahrheit ebnen konnten“ (BeY 2002: 165). Der Prophet ist als Botschafter der Religion des Friedens gezwungen, sich des Mittels des Krieges zu bemächtigen, eine Vorstellung, die an der des gerechten Krieges des Augustinus von Hippo erinnert. EB betont jedoch, dass das letztliche Ziel der Frieden gewesen sei (2002: 393). Muḥammad wird in seinem politischen Dasein als besonders begnadeter Mensch präsentiert: „Mohammed war das gegeben, was nur wenigen Propheten, Denkern, Philosophen und Gottsuchern vor und nach ihm vergönnt war: Der Sprung in die Praxis“ (2002: 181).

\section{Muḥammads Staat}

Noussimbaum unterscheidet in seiner Beschreibung zwischen der Staatswerdung, die im Politik-machen besteht und dem Staatsgebilde als realisierte Utopie. Moral ist in diesem Staatsgebilde zentral. Denn der Islam basiere ,als Staatsbildung auf moralischem Fundament“ (2002: 202). Die Weltmacht des Islams garantiere verschiedene Ziele:

- die Rettung von der Sünde

- die Verbreitung von Gottes Wort

- Zerstörung der Götter des Unglaubens

- Schutz von Kirchen, Moscheen und Synagogen (2002: 207)

Dieses Staatsgebilde gründe nicht auf politischer Macht, sondern auf einer Überzeugung: „Das Imperium Mohammeds hatte zum Fundament den Geist, deshalb überlebte es seinen Gründer" (2002: 372). Bevor der utopische Staat aber errichtet wurde, mussten schwere Wege beschritten werden. Der Gesandte Gottes habe sich hierzu irdischer Macht zu bedienen und den Sumpf der Politik zu durchschreiten gehabt (2002: 207). Die Begriffe der Macht und Politik erhalten hier bei EB eine negative Konnotation. Dies lässt sich womöglich aus seiner eigenen Biographie erschließen, war er doch lange auf der Flucht und musste unter dem Joch der Politik leiden (ReISS 2008: 92-128). Weltliches Ziel Muhammads sei zur Erreichung dieser Ziele von Anbeginn an aber die Ergreifung der Macht in Medina (2002: 195) gewesen, womit Macht wieder zu einer positiven Kategorie wird. Diese gespaltene Zugang zu Macht und Politik zeigt eine Zweiteilung des Machtbegriffs. Die Macht in Medina wird, wie wir später noch sehen werden, zum gerechten Staate Gottes (2002: 386) als ideale Herrschaftsform führen, während der Weg zur Macht ganz nach Machiavelli auch mit Gewalt durchgesetzt werden könne. Die Staatswerdung unter Muḥammad wird mit starkem Bezug auf seine Person erzählt. So sei der Bund der Brüderlichkeit, der Mekkaner und Medinenser miteinander vereinte, die Grundlage für, ,die einheitliche Gemeinde, Gama'a al-Islam, der Kern eines Staates, der weithin sichtbare Ausdruck der Macht des Propheten“ (BEY 2002: 200). Mittelpunkt des Staates war der Darstellung EB's zufolge die erste Moschee, die nicht nur als Gebetshaus, sondern auch als Versammlungsort diente (2002: 200). EB beschreibt dieses Organisieren des Propheten mit folgenden Worten: „Um- 
ringt von kampfbereiten Gläubigen, fühlte sich der Prophet in Medina von Anfang an als Träger einer Macht, und diese Macht wollte er organisieren“ (2002: 198f.). Muhammad sollte schlussendlich eine „zu allem entschlossene Armee der Muhagirun und Ansar“ aufgebaut haben, was ihn zum Herrscher, Machthaber werden ließ, der sich auf den Weg machte, „den Staat Gottes zu bauen“ (2002: 204). Auch hier steht im Zentrum der Erzählung wieder die Führung. Analog zur Darstellung des Propheten als kalkulierenden Staatsmann (2002: 191) war auch die Darstellung der Staatswerdung auf den Propheten zugespitzt. Der Prophet war aber nicht nur Staatsoberhaupt, er hatte bei EB auch eine ,geheime Organisation, die sich über alle Wüsten Arabiens erstreckte“, um ihm Informationen über die politische Lage zu geben, gegründet (2002: 294). Wie dieser Topos der Geheimorganisation entstand, ist rätselhaft. Im Unterkapitel „Die Entstehung des Staates“ wird Ludwig XVI mit den berühmten Worten L'état, c'est moi zitiert, um am Ende dieses Kapitels mit den Worten zu schließen: „So begann der Privatmann Mohammed Gesetze zu diktieren. So entstand aus dem Nichts ein Staat. So begann die Theokratie, so entstand das Muster aller islamischen Staaten, dessen Wirkung bis in die Gegenwart reicht“ (2002: 193-206)

An dieser Stelle wird der islamische Staat des Propheten als ein autokratischer beschrieben. Der Prophet ist der Islam, der Staat ein islamischer, also Staat des Propheten als Quelle des Islams: „In der Stadt herrschte das Wort des Propheten, das Wort des Islam“ (2002: 207), und Medina wird - rein deskriptiv - zur „theokratischen Despotie“ (2002: 229). So wird die Verschriftlichung der Verfassung, wie der Vertrag von Medina hier genannt wird, als erster Akt Muhammads als „Staatsmann“ dargestellt (2002: 204). Dieses ursprünglich als kitāab verfasstes Dokument (LECKER 2004) wurde von muslimischen Wissenschaftern - speziell von Muhammad HAMIDULLAH - zur ersten geschriebenen Verfassung hochstilisiert (HAMIDULLAH 1986). Die höhren Ziele des islamischen Staates sollten mit der unmoralischen Politik erreicht werden. Hier erhält die besondere Sicht auf den Propheten als Mann, der „,von jeder Sünde eine begeht und von jeder Sünde eine bereut und seine Reue verkündet" (2002: 153), einen Sinn. So meint EB in Bezug auf die amoralische Politik: „Mohammed musste diesen Sumpf durchschreiten. Mord, Verrat, Treubruch lagen in diesem Sumpf; wer ihn durchschritt, musste fremdes Blut vergießen, musste Schmutz und Sünde auf sich nehmen, musste ebenso brutal und listig wie streng und weise sein" (2002: 207).

Denn der Weg der Macht, so war sich EB sicher, führe durch „den Sumpf der Sünde“ (2002: 208). Hiermit erhält die Theorie der Sündhaftigkeit des Propheten ihre Schlüssigkeit. Muhammad ist schlussendlich sündenfrei (2002: 208), muss aber von jeder Sünde eine begehen, und um die Welt vor der Sünde zu retten (2002: 207), muss er sich der Macht bedienen, um Gerechtigkeit zu schaffen. Als Hilfsmittel war ihm das Schwert gegeben, das den Propheten Muhammad im Gegensatz zu vielen anderen, ihm vorausgehenden Propheten kennzeichnete (2002: 209). Ganz in orientalistischer Manier wird hier die Verbreitung des Islams über das Schwert und nicht über das Wort erzählt (2002: 209). EB's Politikverständnis entspricht hier einem machiavellistischen Grundzug: Macht mit jedem Mittel zu erlangen. Die Mittel der Machtergreifung dienen aber dem Erhalt dieser: „Sünde und Mord, Raub und List lagen auf dem Weg zur Macht. Jetzt bleiben sie augenscheinlich hinter dem Propheten. Er hatte sie überwunden. Unumschränkt herrschte er über das reiche Medina“ (2002: 299). Die Ära der negativ konnotierten Macht und Politik im Sinne der Phase der Staatswerdung geht zu Ende. Die Sündhaftigkeit ist zudem vermutlich aus EB's Biographie 
heraus zu erklären. Denn sein Leben war hinsichtlich des Umgangs mit der körperlichen Liebe zu einer Frau geprägt von einem an sich selbst gestellten Vorwurf. Will man Kurban Saids „Der Mann, der nichts von der Liebe verstand“ als teilweise autobiographische Erzählung verstehen, wie Wilfried Fuhrmann es tut, so sind die untenstehenden Stellen hilfreich für unser Verständnis des Topos der Sünden:

„Ich verachtete mich tief. Wenn ich in der grauen Dämmerung des anbrechenden Morgens nach Hause ging, quälte mich der Gedanke, dass ich eine, Geliebte 'besaß, eine regelrechte Geliebte. [...] Es blieb nicht bei der ersten. Andere folgten. Nicht viele, aber alle schienen die gleiche Art zu haben, wie aus einem Holz geschnitzt. [...] Es war immer das alte Gefühl: irgendwo tief im Inneren lebte eine Verachtung für all die Frauen, die sich mir näherten, ohne die Absicht zu haben, Kinder auf die Welt zu bringen." (Fuhrmann 2008: 14f.) Und an anderer Stelle heißt es verächtlich und beängstigt: „Gott beschütze uns Männer aus dem Orient - vor der Liebe der westlichen Frau“ (2008: 45). EB beschreibt seine Liebesaffären als persönliche Schwäche. Er gibt sich der Verführung und dem Genuss hin, wenn auch nicht weiter im Detail darüber gesprochen wird. ${ }^{16}$ Vor diesem Hintergrund erscheint die eigentümliche Erzählung der Sündhaftigkeit des Propheten Muhammad wie eine Projektion. Zu guter letzt herrscht dieser durch den Sumpf der Politik geschrittene Prophet jedoch mit Milde (2002: 321). In der spätmedinensischen Ära erhält der Prophet zur Beschreibung des Staatsgebildes eine weitaus positivere Konnotation:

Es war Mohammeds Art, Vergehen, Beschimpfungen, ja sogar Anschläge, die sich gegen seine Person richteten, gnädig zu vergeben und womöglich zu übersehen. Unerbittlich, voll eiserner Brutalität war er aber gegen jeden, der sein Werk, seinen Koran und seinen Staat anzugreifen versuchte. Hier kannte er keine Milde, sondern verwandelte sich aus einem friedlichen Prediger in einen erbarmungslosen Rächer, in einen blutrünstigen Despoten, der sich jeder List und jedes erdenklichen Mittels bediente, um selbst den leisesten Spott über den Glauben zu ahnden. Allerdings verstand er auch hier zu warten, zu überlegen und den richtigen Augenblick auszunutzen. (BEY 2002: 230f.)

Muhammad wird in diesem Sinne als Mensch dargestellt, der zwischen der Sphäre des Göttlichen und des Privaten unterschied. Wer gegen den Staat arbeitete, der wurde hart bestraft. So werden die Geschichten der Jüdin Zainab und des Quraišiten Habbār erzählt, denen er sich in Milde zuwandte. Erstere versuchte den Propheten selbst zu töten. Letzterer tötete die Tochter Muhammads. Beide bekundeten, den Islam annehmen zu wollen, worauf der Prophet sie begnadigte und ihnen das Leben schenkte (2002: 312f.). EB schließt diese Erzählungen mit der Anmerkung ab, dass ,Milde und nicht Blut [...] die Welt des Islam beherrschen“" sollten (2002: 322). Das Staatsgebilde selbst war also voll Milde, die Staatswerdung aber voll Härte. ${ }^{17}$ So heißt es auch in der Einschätzung EB's über die Bedeutung

16 Derzeit sind lediglich drei von sechs Heften aus der autobiographisch gefärbten/inspirierten Erzählung „Der Mann, der nichts von der Liebe verstand“ einsehbar. Das dritte Heft wurde von Wilfried Fuhrmann im Jahre 2002 auf Basis der online gestellten eingescannten Originalskripten, die unter 〈www.tomreiss.info> abrufbar sind, veröffentlicht. Die restlichen beiden Hefte sind unter $<$ www.tomreiss.info > einsehbar.

17 Besonders bemerkenswert ist hier das Kapitel „Terror“, in dem Bey über dieses Mittel als Politik des Propheten spricht (EB, 2002: 228-239). 
des Krieges bei Muhammad: „Das Ziel war nicht der Kampf, sondern der Friede. Der endgültige Friede der durch die Regeln eines einheitlichen Glaubens gebändigten Menschheit. [...] Er dachte an den Frieden der Welt“ (2002: 393). Interessant ist hier die Deutung Tom REISs', der den Grund der Konversion zum Islam darin sieht, dass EB ,auf diese Weise die Hoffnung auf ein friedliches Miteinander vieler Völker wiederzufinden" suchte (REISS 2008: 243).

\section{Esad Beys Staatstheorie - die „theokratische Demokratie“}

EB's Bedienung unterschiedlicher Begrifflichkeiten zur Charakterisierung des Staates ist dabei sehr weitläufig. Sie reicht von der theokratischen Despotie (BEY 2002: 229) über theokratische Demokratie (2002: 183, 254), Republik Gottes (2002: 229) bis hin zum theokratischen Sozialismus (2002: 342) und gerechten Staate Gottes (2002: 386). Sich an diesen Begriffen zu orientieren wird wenig hilfreich sein, um zu verstehen, was EB genau unter dem Staat Gottes (2002: 204) subsumierte. Einen Zug der „theokratischen islamischen Demokratie, des demokratischen Staates Gottes" besteht für EB in ihrem Kontrast zu einer „erblichen, orientalischen Monarchie“ (2002: 287). Das Erbschaftsprinzip war für ihn mit den islamischen Vorstellungen von Staatlichkeit unvereinbar. In diesem Sinne - so meine ich - ist seine Affinität zu den al-hawāriğ zu verstehen. Sie sind für ihn eine der drei Bewegungen, die versuchten, „die Idee vom freien Staat Gottes zu retten“ und waren für ihn „die direkten Erben des Propheten [...], die edelsten unter den Gläubigen“ (2002: 386, 398). Denn es waren die al-hawāriğ, die in der Frühzeit des Islams den Standpunkt vertraten, dass die Führung der muslimischen Gemeinschaft allen Muslimen offen sein sollte, ohne Rücksicht auf deren Herkunft oder Rang. Der halïfa sollte auf Basis freier Wahlen ernannt werden und keine Sünden begehen, da ein Sündiger Kāfir ist (SoUAIAIA 1999: 15, also SCHLEIFER 1983). Auch EB meint, dass der halif $a$ durch den „Consensus omnium [...] durch allgemeine Anerkennung des Volkes“ gewählt wird (EB/VON WEISL 1936: 38). Dass für EB die hiğra den zentralen Wendepunkt in der politischen Formierung des Islams war, zeigt er an folgender Stelle: „Der Islam als Glaube lag fest und sollte jetzt den Staat bilden. [...] Das Schwert und der Koran sollten von nun an in der Welt herrschen" (BEY 2002: 176). Mit einem positiven Bezug zum Kämpferischen wird die Staatswerdung des Islams zur selbstverständlichen Notwendigkeit erklärt (2002: 166). Es bleibt aber nicht beim medinensischen Staat alleine:

[...] Mohammed [...] beanspruchte [...] die absolute, durch nichts geschmälerte Herrschaft über die gesamte Menschheit. Diese Forderung ergab sich mit absoluter, logischer Konsequenz aus den toleranten, biegsamen Grundthesen des Propheten. [...] Denn der Islam hatte Anspruch auf Weltherrschaft. Jetzt in Medina sollte dieser Anspruch durchgesetzt werden. (BEY 2002: 181)

Die absolute Weltherrschaft, die EB hier anspricht, kann hier nicht als eine unterdrückende verstanden werden. Zum Ableben des Propheten schreibt EB, Muhammad habe es geschafft, dass der Islam als Religion in vielen Teilen der Welt bekannt geworden ist und herrschte (2002: 370). Die Weltmacht habe sich nicht auf die politische Macht berufen, sondern habe den religiösen Inhalt zum Kern gehabt (2002: 372). Diese Herrschaft implizierte etwa keine Zwangsmissionierung. EB ist in der Auslegung von Sure 5, Vers 73 sogar freimütiger als viele klassische Koranexegeten und meint, dass im Islam „wohl als einzige 
Weltreligion [...] den Angehörigen fremder Glaubensbekenntnisse der Weg zur Rettung nicht verschlossen ist“ (2002: 179). Er verstand den Weltstaat jedenfalls als gegen jede nationale Orientierung gerichtet, da der Islam eine Religion für alle Menschen und nicht nur für die Araber war (2002: 259). In diesem Sinne schrieb er 1931 in einer deutschen Zeitung: „Die vielen Völker, die ich besucht, die vielen Ereignisse, die ich gesehen habe, haben mich zum vollendeten Kosmopoliten erzogen" (EB 1931: 4, zit. nach ReISS 2008: 273). So meint er am Ende der Erzählungen über die Feldzüge des Propheten: „Der Gründer eines Nationalstaates hätte sein Werk als vollendet ansehen können. Der Nationalstaat aber war nicht die Idee Mohammeds. Seit dem ersten Tag der Sendung hatte er die Weltherrschaft des Islam verkündet“ (BEY 2002: 347f.). Ebenso sah EB sich als gegen jede Art des Nationalismus gerichtet (ReISS 2008: 299). Der arabische Staat war kein Ziel, sondern nur eine Etappe auf einem langen Wege. So sollte der Panislamist EB den Propheten verstehen weshalb er in der Biographie vor der Eroberung Mekkas schreibt:

Für Mohammed selbst bestand kein Zweifel mehr, dass er bald der alleinige Herrscher über Arabien sein würde. Für den einstmals so ärmlichen mekkanischen Kaufmann wäre das eine große Befriedigung gewesen, für den Propheten Mohammed, für den letzten Gesandten Gottes auf Erden, war das nur der Anfang, nur ein bescheidener Auftakt zu einer viel größeren Laufbahn. [...] seit der ersten Predigt war der Islam universal gedacht. Gott hatte seinen Propheten allen Völkern der Welt als den letzten Verkünder der Wahrheit gesandt. (BEY 2002: 314)

EB charakterisiert dieses Staatsgebilde als einzigartig im Kontext des „alten Orients“ von damals. Für ihn war „der Staat des Islam ein demokratisches Gebilde“. Muḥammad ,zerrüttete das Staatswesen, den Partikularismus der freien Sippen" und präsentierte anstelle dieser „eine große Sippe des Islam, die zuerst Arabien und dann die ganze Welt zusammenfassen sollte" (2002: 182). Muḥammad ist für ihn also nicht nur in historischer Hinsicht der Prophet des alten Arabiens, sondern Träger einer universellen Botschaft. Zentral ist für EB hier die Gleichwertigkeit, Freiheit und Gleichberechtigung aller Gläubigen (2002: 183). EB's Demokratieverständnis bezieht sich demnach auf die Stellung der Menschen untereinander im Sinne von Politik als einer „Kunst der Führung und Verwaltung der öffentlichen Aufgaben im Interesse der Gemeinschaft der Bürger" (NOHLEN/SCHULTZE 2002: 657). Es ist die „These der absoluten Gleichberechtigung der Menschen“, die für EB hier „zum ersten Mal im Weltmaßstab entwickelt" wurde (2002: 183). Es geht also in einer historischen Perspektive um die Gleichstellung aller „Rassen, Klassen und Schichten“, die „für Jahrhunderte in diesem weltumfassenden System untertauchten“ (2002: 183). Für EB muss diese Ordnung des islamischen Weltstaates samt seiner Anschauung der Egalität mitten im Zeitalter totalitärer ideologischer Ordnungen und faschistoider Ungleichheit, die die Menschen in Unter- und Übermenschen einteilte (HOBSBAwM 1998: 184-227), wie ein paradiesischer Ort einer realisierten Utopie gewesen sein. Denn EB selbst war stets in Vereinigungen organisiert, die sich gegen den Bolschewismus und den Faschismus richteten (REISS 2008: 300). Die Verwendung des Begriffs des ,theokratischen Sozialismus“ erhält in diesem Kontext der Betonung der Gleichheit aller Gläubigen vor Gott sowie deren Gleichheit vor dem Gesetz (2002: 342) Bedeutung. Muhammad schuf nach EB einen ,neuen Begriff: den der allumfassenden Bruderschaft der Muslim“ (EB /Von WeISL 1936: 15). Der „Glaube an die Gleichheit der Menschen" ist EB besonders teuer und wird als eines von vier 
„Dogmen“ neben dem Glauben an Gott gestellt (BEY 2002: 394). Auch an anderer Stelle meint EB, die Idee des Staat Gottes sei „die Idee von der Einheit der Menschen im Islam“ (2002: 375). Muhammads Vermächtnis sei der Versuch „,der Vereinigung der Menschheit“ gewesen (2002: 408). Diese Egalität der Menschen wird unter der Voraussetzung einer hierarchischen Unterwerfung unter Gottes Gesetz verwirklicht. EB meint,

[...] die Demokratie des Islam war eine theokratische Demokratie. Die Menschen waren Sklaven Gottes und als Sklaven einander gleich. Eisern waltete über jedem einzelnen das Gesetz Gottes. Die Gleichheit des Islam war nicht mit Freiheit verbunden, wie auch der vorislamische Araber alles andere als frei war. [...] Unterwerfung des Menschen unter ein ehernes und einfaches Gesetz, vor dem alles, was sich Mensch nennt, gleich gilt (BEY 2002: 183f.).

Die Frage der Gleichheit ist ein immer wiederkehrender Topos in der Prophetenbiographie EB's (2002: 194, 339f., 418). Das Gesetz Gottes wird bei EB als „tolerante lebensbejahende Gesetzgebung“ definiert (2002: 403). Es herrscht das „Primat des menschlichen Geistes", wie EB den Begriff des iğtihäd beschreibt (2002: 404). Nach EB hatte der von Muhammad geschaffene Gottesstaat in mehrerer Hinsicht eine Vorreiterrolle eingenommen. So etwa wurden von ihm ,als Erster in der Weltgeschichte Gesetze humaner Kriegsführung" geschaffen (2002: 317). Ganz entgegen den biblischen Anweisungen der „,endgültigen Ausrottung des Feindes" (1 Sam 15,3 und Ez 9,6) sowie den Kriegen der Perser und Byzantiner war Muhammads Ziel ,nicht die Eroberung, sondern die Organisierung der Welt“ (2002: 317f.). ${ }^{18}$ An anderer Stelle meint er hinsichtlich der Herrschaft: „Denn die Herrschaft über Menschen - was ist sie? Staub! Kostbar ist nur die Herrschaft über die Seelen!“ (EB/Von WeISL 1936: 58). Es musste also ein Staat sein, in dem die Seele des Islams lebt, in der der Islam und Gott geliebt werden (EB/VON WEISL 1936: 24). Dieser Staat bildete nach EB eine einheitliche Form von „Gesetz, Sprache, Religion, Wirtschaftsform" aus (2002: 403) und kreierte den Begriff der universalen Bildung, in dessen Zentrum das „Primat des menschlichen Geistes, das iğtihād“" stand (2002: 404f.). EB geht nicht weiter darauf ein, was er mit universaler Bildung meint. Interessant ist in dieser Hinsicht, dass auch hier ein Topos Erwähnung findet, der in der Moslemischen Revue von Bedeutung war: Der vom Islam als Ausdruck des Ideals von ,progressiver Wissenschaft und Bildung“" (MOTADEL 2009: 118).

Muhammads Staat kannte nach EB eine „Beamtenschaft und Polizei“, die später unter dem Kalifen Umar weiterentwickelt wurde (BEY 2002: 344) sowie andere Institutionen wie jene der Finanzen und Justiz, die zur Zeit des zweiten Kalifen Umar erweitert wurden (2002: 378). Geistliches und Weltliches waren miteinander verwoben, so EB. Der Gouverneur war stets auch Imam und dieser wiederum Kadi (2002: 342f.). Auch einen Oberbefehlshaber ernannte Muhammad noch vor seinem Tod, nachdem er zu schwach für diese Tätigkeit wurde (2002: 365). Im Zentrum des islamischen Staates steht eine zentrale Person, zur Zeit Muhammads der Prophet selbst, danach die Kalifen. So meint EB über Umar, den er den „Paulus des Islam“ nennt, der „die Idee vom einheitlichen demokratischen und

18 Dem Kreuzrittern wirft er auch vor, in Jerusalem ein „fürchterliches Blutbad“ vollbracht zu haben, während Umar im Zuge der Eroberung Jerusalems wie auch später das Christentum gesetzlich schützen ließ (BEY 2002: 380). 
dennoch absolutistischen Staate Gottes" verwirklichte (2002: 378f., 382), dass gerade dieser die Ideale des Propheten hochhielt. Er beschreibt ihn als einfachen Menschen, der sich nicht dem Luxus hingab, denn ,strenge Zucht, Bescheidenheit und das Gebet sollten die Führer des neuen Staates schmücken“ (2002: 381). Das nicht erbliche Amt des Kalifen, der nach EB geistliche und weltliche Macht in einem vereint, wird von einer „Republik der Weisen [...], den weisen Korankennern, gewählt". Die Herrschaft kann dem halïfa wiederum durch einen „Spruch der Weisen, der Ulema“" entzogen werden. Die mögliche Absetzbarkeit durch den „Richterspruch der Ulema“ ist für EB Ausdruck des „Wahlprinzips“, das sich nicht auf die Masse erstreckt, sondern auf diesen Weisenrat bezieht. Grund einer Kalifenentthronung ist etwa das Begehen einer Sünde im Sinne einer Verletzung eines „ausdrücklichen Gebots des Korans“. Auf diese Weise, so EB, verstand es der Islam, „eine absolute theokratische Diktatur auf Lebenszeit mit einer weitgehenden republikanischen Demokratie zu vereinen“. Diese Ordnung wurde real nicht lange geführt, herrsche aber in der Theorie, so EB (2002: 398f.). Dass sie für ihn eine lebendige Theorie darstellt, zeigt sich auch in seinem Buch „Allah ist groß“, wo er über den damaligen saudischen König Ibn Sa 'ūd meint, „er setzte dort an, wo der Prophet endete, und das lebendige Wort des Korans erwies sich mächtig genug, um im zwanzigsten Jahrhundert ein großes Reich zu führen“ (BEY/VON WEISL 1936: 103-329).

\section{Die Wiederherstellung islamischer Herrschaft}

Mit dem 3. März 1924 war für EB die Idee des islamischen Staates durch die Hände des Mustafa Kemal Pascha gestorben (BEY 2002: 373ff.). Tot war sie aber nicht, wie EB betont (2002: 401). Tschingis Khans Verwüstung, der ökonomische Niedergang der islamischen Welt durch die Entdeckung Amerikas sowie die Schließung der sog. „Pforte der Erkenntnis“ waren für EB die Gründe für den Verfall der islamischen Welt (2002: 409f.), welcher Atatürk lediglich den letzten Gnadenstoß versetzte (2002: 411). Als 1932 aber das Kalifat abgeschafft war, indem die Macht des Kalifen Abdülmecid verschwunden war, sah EB trotzdem einen Lichtblick für die islamische „Wiedergeburt“. EB selbst zeigte zu seinen Lebzeiten durch sein öffentliches Auftreten mit Fez, einem Symbol, das ebenso wie der Ehrentitel „Bey“ offiziell verboten wurde, seine Verbundenheit mit der alten islamischen Ordnung (2008: 243). Dieser Fez wurde ab dem späten 19. Jahrhundert von indischen Muslimen getragen und galt ,als Symbol einer panislamischen Verbindung“ (MOTADEL 2009: 105). Seine Verbundenheit mit der alten politischen Ordnung der muslimischen Welt scheint insofern mehr als naheliegend. Sultan Abdülhamid rühmte EB dabei besonders als einen Mann, der den alten Geist des Islams ins islamische Reich zurückzubringen versuchte, nicht zuletzt, weil er sich vom Schöpfer des Panislamismus, den er selbst vertrat, „zum bewußten Kalifat" bekehren ließ (EB/VON WeISL 1936: 43-61). Ǧamāl ad-Dīn al-Afğān̄̄ war für EB dieser erste Panislamist, den er in marxistischer Anlehnung den internationalistischen Slogan „Mohammedaner aller Länder - vereinigt euch!“ zuschreibt (EB/VON WeISL 1936: 53). Ihm ging es im Verständnis des EB um eine Erneuerung des Glaubens in der muslimischen Welt, die sich mit den technischen Fortschritten Europas paaren sollte (EB/VON WeISL 1936: 55f.). In diesem Sinne kann EB nicht als reiner Kulturpessimist abgetan werden, für die die „Maschine ein Ausdruck von kaltem, berechnendem Rationa- 
lismus" war und aus deren Sicht die mechanisierte Industrie ein Zeichen von Entfremdung und Erniedrigung war (HERMAN 1998: 223). Für ihn bestand die Möglichkeit der Erneuerung zu dieser Zeit nicht in der Rückkehr des osmanischen Sultans und Kalifen, dessen Geschichte der Entwurzelung sein Roman „Ali und Nino“ (1937) erzählen könnte, sondern in der Person Ibn Sa'ūd, dem damaligen König von Nadschd, Asir und dem Hịğāz (BEY 2002: 411). Doch die Ära des Osmanischen Reichs ist für EB vorüber: „Der Islam des Kalifats ist tot - der Islam der Wüste aber lebt" (EB/VON WEISL 1936: 33), nachdem auch andere Kämpfer für Abdülhamids Panislamismus wie der Senussi-Orden versagt hatten (EB/VON WeISL 1936: 103-112). Die Bewegung der saudischen Ihwān des 'Abd alWahhāb entsprach seiner Ansicht nach dem Vorbild des Propheten Muḥammad am besten. EB zeichnet eine Parallele zu Muhammads Zeit und der Bewegung des Muhammad Ibn Sa ùd:

Denn gerade jetzt erleben wir ein ähnliches Schauspiel, wiederum kämpfen verhältnismäßig kleine, schwache, schlecht ausgerüstete und geldlose orientalische Mächte islamischen Glaubens gegen Weltreiche - und wiederum erliegt das stärkere, größere, reichere und viel höher kultivierte Europa dem Angriff. Wieder weicht es Schritt für Schritt vor den Kriegern der Wüste zurück (BEY/VON WEISL 1936: 18).

In dem Satz „Der Hof der Kaaba war Mittelpunkt der panislamischen Politik Abdul Hamids" (EB/VON WEISL 1936: 307) erklärt sich dann auch die zentrale Rolle des Topos der arabischen Wüste. Wieder waren es die primitiven wahhäbiyya, die das Land aus den Händen der verschwenderischen Könige nahmen, den Aberglauben zerstörten und den reinen Monotheismus etablierten, um später unter der Herrschaft des Islams zum Ideal der Synthese von Glauben und Moderne zu werden (EB/VON WEISL 1936: 307-342). Denn, so beschrieb EB den wahhabitischen Staat, ,das Fundament des Staates blieb der Koran, und dieser Staat ist und bleibt die legitime Fortsetzung des Staates Gottes, den der mekkanische Prophet den Ahnden der heutigen Ihwwān vierzehnhundert Jahre vorher verkündet hat" (EB/VON WEISL 1936: 302), während er gleichzeitig meinte:

Ibn-Sauds welthistorisches Verdienst besteht darin, als erster gezeigt zu haben, dass es auch anders geht - anders nämlich als in Europa und in Amerika. Daß es möglich ist, einen wehrhaften modernen Staat aufzubauen, ohne die Schattenseiten der abendländischen Zivilisation, ohne Nachtlokale, Theater, Weinschenken, ohne Cocktails, Frauenprobleme, Gassenhauer und Tänze (EB /VON WEISL 1936: 337).

EB verwendet hier ein klassisches Genre der kulturpessimistischen Zivilisationskritik (HERMAN 1998: 54ff.), die hier als dekadent und egoistisch portraitiert wird. Mit dem Königreich Saudi-Arabiens würden ,die Ideen Abdul Hamids und des Sayd Dschemal Eddin ${ }^{19}$ [...] damit ihre modernste und derzeitig endgültige Verkörperung“ finden (EB/VON WEISL 1936: 341). Denn der saudische König „senkte die Steuern, er erhöhte die Gehälter, er öffnete die Gefängnisse“" (EB/VON WEISL 1936: 328). Sie machten den qur'ān und die sunna zum Maßstab der Lebensordnung. Die Rückeroberung Mekkas durch Ibn Sa ūd mithilfe der religiösen Lehren des 'Abd al-Wahhāb sollte die Grundlage für eine Ausbreitung des Islams von seinem Kernland sein. Das Motto der Ihwān-Bewegung fasst er fol-

19 Gemeint ist Ğamāl ad-Dīn al-Afğān̄i 
gendermaßen zusammen: „Beten und exerzieren“. Dabei stellt er die Ihwān-Bewegung als sehr tolerant dar. ${ }^{20}$ Ein Wahhabitenreich, das durch das Sesshaft-werden der Nomaden einen Schritt der Reform unternommen hat, um die Macht des modernen Islams wieder auf die Weltbühne zu bringen. Euphorisch urteilt EB, der neue Staat sei „dreimal so groß [...] wie Deutschland“ (BEY 2002: 412-418). Für ihn war dieser Wahhabitenstaat Inbegriff für Reform, Rettung und Erfüllung zur Errichtung des gerechten Staat Gottes (BEY 2002: 417).

\section{Literatur}

AlI, Muhammad Mohar. 1997. Sirat Al-Nabi and the Orientalists. With Special Reference to the Writings of William Muir, D. S. Margoliouth and W. Montgomery Watt, vol. 1A: From the Background to the Beginning of the Prophet's Mission. King Fahd Complex for the Printing of the Holy Qur'an, Madina Munawwara.

Ali and Nino: The Business of Literature $\rightarrow$ BLAIR (ed.) 2011.

AsAD, Muhammad. 2009. Der Weg nach Mekka. Düsseldorf, Patmos Verlag. Originalausgabe: 1952, New York, Simon \& Schuster Inc.

Azerbaijan International $\rightarrow$ BLAIR (ed.) 2011.

BELL, Richard. 1930. »Who were the Hanifs?« Muslim World 1930: 121f.

Benaboud, Muhammad. 1986. »Orientalism on the Revelation of the Prophet: the Cases of W: Montgomery Wann, Maxime Rodinson and Duncan Black MacDonald.« The American Journal of Islamic Social Sciences, vol. 3,2: 309-326.

BeY, Esed. 2002. Mohammed. Komet Verlag, Berlin. (Originalausgabe Berlin: Kiepenhauer, 1932).

_ I Von WeISL, Wolfgang. 1936. Allah ist groß. Niedergang und Aufstieg der islamischen Welt von Abdul Hamid bis Ibn Saud. Verlag Dr. Rolf Passer, Leipzig \& Wien.

BLAIR, Betty (ed.). 2011. »Ali and Nino: The Business of Literature. Who Wrote Azerbaijan's Most Famous Novel?«Azerbaijan International, 15,2-4 [Themenheft].

BRunNeR, José / SHAI, Levi. 2009. Juden und Muslime in Deutschland. Recht, Religion, Identität. Tel Aviver Jahrbuch für deutsche Geschichte. Wallstein Verlag, Göttingen.

Euben, Roxanne L. / ZAman, Muhammad Qasim. 2009. Princeton Readings in Islamist Thought. Texts and Contexts from al-Banna to Bin Laden. Oxford University Press, Princeton.

FuHRMAnN, Wilfried. 2008. Ist Kurban Said der Mann, der von der Liebe nichts verstand? Selbstverlag, Potsdam.

FüRTIG, Henner (ed.). 2001. Islamische Welt und Globalisierung. Aneignung, Abgrenzung, Gegenentwürfe. Ergon, Würzburg.

Hamidullah, Muhammad. 1986. The First Written Constitution in the World. $2^{\text {nd }}$ edition. Mohammad Ashrof, Lahore. (Original: 1941).

Herman, Arthur. 1998. Propheten des Niedergangs. Der Endzeitmythos im westlichen Denken. Ullstein Buchverläge, Berlin. (Originalausgabe New York: Free Press, 1997).

Hobsbawm, Eric. 1998. Das Zeitalter der Extreme. Weltgeschichte des 20. Jahrhunderts. DtvVerlag. München.

HöPP, Gerhard. 1994. »Muslime unterm Hakenkreuz. Zur Entstehungsgeschichte des Islamischen Zentralinstituts zu Berlin e.V.«Moslemische Revue 14,1: 16-27.

20 Esad Bey ist sich dabei durchaus des Strafgesetzes bewusst. Er widerlegt die bereits damals anzutreffende Kritik, Saudi-Arabien wäre ein „,fanatischer Staat, voll mittelalterlicher Grausamkeit“, indem er meint, dass Sünden im privaten Raum vollzogen werden können, jedoch in der Öffentlichkeit geahndet werden (BEY/VON WEISL 1936: 330). 
1996. »Zwischen-Aufenthalt. Mohammed Essad-Bey in Deutschland. Rekonstruktion eines Lebenslaufs «. Berliner LeseZeichen, 4,i-ii: 55-60.

. 1997. »Mohammed Essad Bey: Nur Orient für Europäer?« Asien, Afrika, Lateinamerika, 25,1: 75-97. - Manuskript zugänglich als pdf unter http://www.zmo.de/biblio/nachlass/hoepp/ 02_01_051.pdf [01.01.2011].

- 2001. »Biographien zwischen den Kulturen. Asis Domet ('Aziz Dumit) und Mohammed Essad«. In: FÜRTIG (ed.) 2001: 149-157.

— . [o.D.]. »Noussimbaum wird Essad-Bey. Annäherung an eine Biographie zwischen den Kulturen« (Manuskript). http://www.zmo.de/biblio/nachlass/hoepp/02_01_089.pdf [01.01.2011].

IBN IsHaQ, Muhammad. 1999. Das Leben des Propheten. Aus dem Arabischen übertragen und bearbeitet von Gernot ROTTER. Spohr Verlag, Kandern im Schwarzwald.

Jansen, Hans. 2008. Mohammed. Eine Biographie. Aus dem Niederländischen von Marlene MüllerHaas. C. H. Beck Verlag, München.

KeRmANI, Navid. 2002. »Krieg führen, Koran lesen, beten. Essad-Beys Geschichte des Islam - ein irritierendes und doch wunderbares Buch«. Rezension in: Zeit Online, http://www.zeit.de/ 2002/51/SM-Islam [01.01.2011].

LECKER, Michael. 2004. The 'Constitution of Medina': Muhammad's First Legal Document. The Darwin Press, Princeton.

Montefiore, Simon Sebag. 2008. Der junge Stalin. Fischer Verlag, Frankfurt am Main.

MotADEL, David. 2009. »Islamische Bürgerlichkeit - das soziokulturelle Milieu der muslimischen Minderheit in Berlin 1918-1939 «. In: BRUNNER/SHAI 2009: 103-121.

NAGEL, Tilmann. 2010. Mohammed. Zwanzig Kapitel über den Propheten der Muslime. Oldenbourg Verlag, München.

Nohlen, Dieter / Schultze, Rainer-Olaf. 2002. Lexikon der Politikwissenschaft, Band 2. Beck'sche Reihe, München.

ReIss, Tom. 2008. Der Orientalist. Auf den Spuren von Essad-Bey. Osburg Verlag, Berlin. (Originalausgabe New York: Random House, 2005).

Rodinson, Maxime. 1975. Mohammed. Verlag C.J. Bucher, Luzern und Frankfurt. (Originalausgabe Paris: Editions Du Seuil, 1961)

RÜCKERT, Friedrich. 2009. Der Koran. Anaconda Verlag, Köln. (Originalausgabe Frankfurt am Main: Verlag Sauerländer, 1888).

SCHLEIFER, S. Abdullah. 1983. »Jihad and Traditional Islamic Consciousness - Part Two«. The Islamic Quarterly (London) 1983,4. <http://www.salaam.co.uk/knowledge/schleifer_2.php>.

SouAIAIA, Ahmed E. 1999. »Transformed Politics«. 〈http://majalla.org/SouAIAIA/papers/khaldun. pdf〉.

SPENGLER, Oswald. 2000. Der Untergang des Abendlandes. Umrisse einer Morphologie der Weltgeschichte. DTV, München. (Originalausgabe München: Beck’sche Verlagsgruppe, 1923).

WegneR, Armin T.. 1942. Tagebücher / abgetippt und online veröffentlicht von Gerhard HöPP. <http://www.zmo.de/biblio/nachlass/hoepp/02_10_136.pdf> [01.01.2011].

Wокоеск, Ursula. 2009. »Wie lässt sich die Geschichte der Muslime in Deutschland vor 1945 erzählen?«In: BRUNNER/SHAI 2009: 121-146.

FARID HAFEZ, Department of Oriental Studies, University of Vienna, Austria

$\checkmark$ farid.hafez@univie.ac.at 